\title{
Congenital Diaphragmatic Hernia with Lung Hypoplasia - A Cause of Sudden Death in a Neonate
}

\author{
Pushpa P. Burute ${ }^{1}$, Vaishali Korade ${ }^{2}$, Swati Belsare ${ }^{3}$ Sadhana Roychoudhury $^{4}$ \\ ${ }^{1}$ Associate professor, Department of Anatomy, Dr. D.Y.Patil Medical College, Pune, DPU Maharashtra, India \\ ${ }^{2}$ Associate professor, Department of Obst.\& Gynaecology, MIMER Medical College, Talegaon, MUHS, India \\ ${ }^{3}$ Professor \& Head, Department of Anatomy, MIMER Medical College, Talegaon, MUHS, India \\ ${ }^{4}$ Assistant professor, Department of Human and Clinical Anatomy, Sultan Qaboos University College of \\ Medicine, Muscat, Oman
}

\begin{abstract}
Sudden unexpected deaths in neonates usually result from underlying natural disease. We report a case of death in a full term apparently healthy female neonate delivered normally at the -M.I.M.E.R. Medical College hospital, Talegaon, Pune, India, who cried after birth, developed cyanosis and died in a few minutes. The foetus was received in the Dept. of Anatomy, M.I.M.E.R. Medical College for embalming and dissection. Detailed examination and dissection revealed congenital diaphragmatic hernia $(\mathrm{CDH})$ with bilateral lung hypoplasia in the newborn. With the advent of better antenatal diagnosis and neonatal care, the chances of survival in $\mathrm{CDH}$ have improved. However, there still remains a significant risk of death and complications in infants with $\mathrm{CDH}$, primarily due to the associated lung hypoplasia. The insult to the lungs is now thought to be an independent, associated finding, due to a common genetic pathway involved in the development of the diaphragm and the lungs, rather than a cause-effect relationship.
\end{abstract}

Keywords - Sudden death, neonate, congenital diaphragmatic hernia, lung hypoplasia, genetic pathway

\section{INTRODUCTION}

Neonatal death is defined as a death occurring within the first 28 days of life. Sudden unexpected deaths in neonates usually result from various congenital anomalies. Congenital diaphragmatic hernia (CDH) is one such anomaly that is associated with pulmonary hypoplasia (underdeveloped lungs) where the affected neonate may present with respiratory distress of varying severity in the first few hours of life. The hypoplastic lungs could be arrested in varying stages of embryonic development. Severe lung hypoplasia in such cases can be a cause of sudden death.

Congenital Diaphragmatic Hernia (CDH) results from defective formation/fusion of the pleuroperitoneal membrane with the other three developmental components of the diaphragm. This diaphragmatic defect occurs about once in 2200 newborn infants [1]. In majority of the cases the defect is on left side (Bockdalek's hernia), $10 \%$ cases right sided $2 \%$ are bilateral [2]. CDH is a life threatening anomaly and a major cause of death in infants. The mortality rate in $\mathrm{CDH}$ varies from 40-62\% [3].

A case of sudden death from congenital diaphragmatic hernia with lung hypoplasia in a newborn is reported.

\section{Case-Report}

An unregistered third para was admitted in the department of Obstetrics and Gynaecology, M.I.M.E.R. Medical College and Hospital, Talegaon Dabhade with labour pains. There was no history of antenatal checkups or ultrasonography during pregnancy. Within an hour an apparently healthy, full-term live born female baby of birthweight $3.4 \mathrm{~kg}$, was delivered normally, who cried after birth. Cyanosis set in within a few minutes. Resuscitation and endo-tracheal intubation was done. However, the cyanosis increased and the baby died withinn a few minutes. The concerned parents expressed a willingness to donate the foetus to the hospital. In accordance with the Anatomy Act, the foetus was received in the Dept. of Anatomy, M.I.M.E.R. Medical College and Hospital, Talegaon, from the Department of Obstetrics and Gynaecology. The neonate was embalmed using routine embalming fluids and subsequently dissected in order to ascertain the cause of sudden death in an apparently healthy neonate.

\section{Observations}

External examination was unremarkable. Birth weight of the foetus was $3.4 \mathrm{Kg}$. Internal examination of thorax showed the presence of a large defect in the left dome of the diaphragm. (Figure 1) 


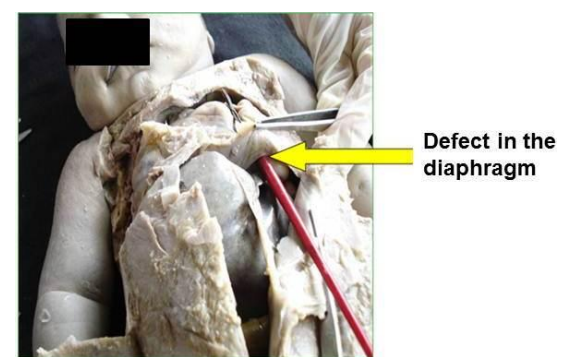

Figure 1: Internal examination showing a defect in the diaphragm on the left side

The right dome was normal. The herniated contents in the thorax included the stomach, the entire small bowel, a portion of the large bowel, the spleen and the entire left lobe of the liver (Figure 2, 3). Hypoplasia of right and left lungs was apparent (Figure 3 and 4). Both the lungs and the diaphragmatic surface of the heart were in contact with the right dome of the diaphragm. The external features of the heart were apparently normal.

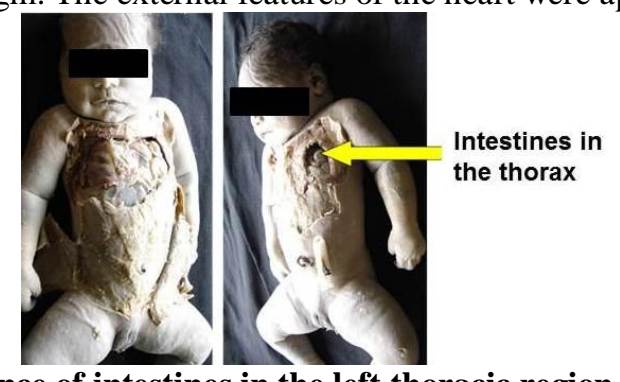

Figure 2: Presence of intestines in the left thoracic region

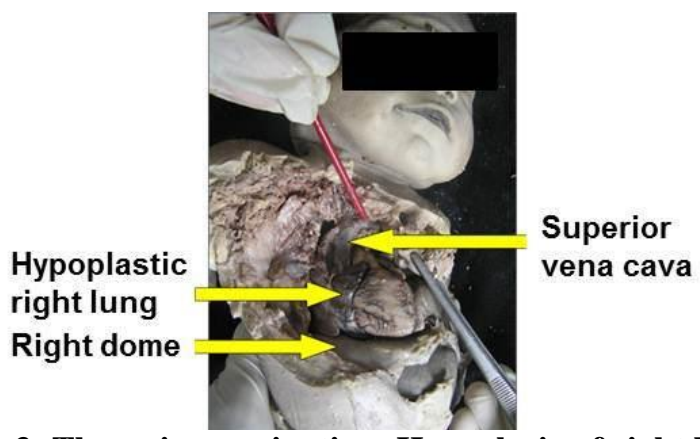

Figure 3: Thoracic examination: Hypoplasia of right lung

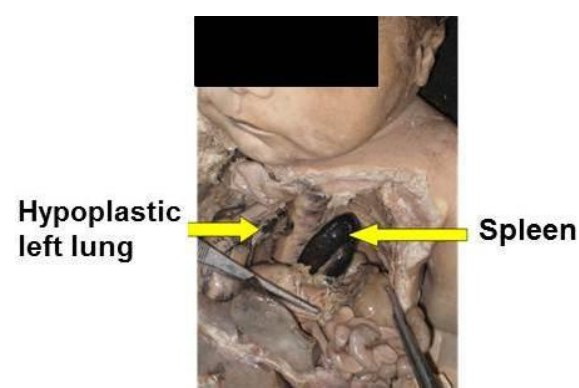

Figure 4: Thoracic examination: Hypoplastic left lung \& Spleen in thorax

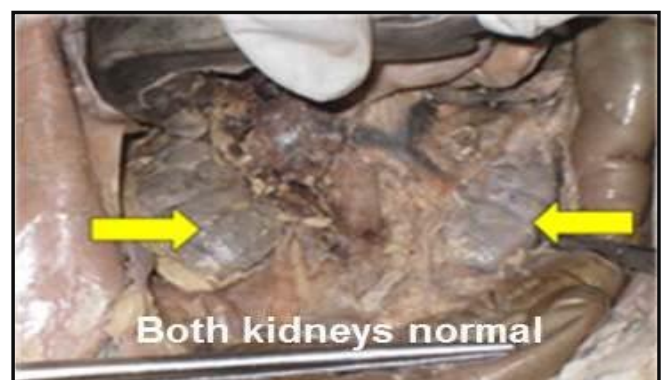

Figure 5: Abdominal examination: Both kidneys were unremarkable. 
The superior vena cava was visualized with the left brachiocephalic vein passing through a large thymus. Abdominal examination was unremarkable, both kidneys being apparently normal in size and position (Figure 5). $\mathrm{CDH}$ is frequently associated with renal agenesis/abnormalities [4]). The cause of death in the neonate was ascertained to be congenital diaphragmatic hernia with bilateral ?primary /secondary lung hypoplasia.

\subsection{Pathogenesis:}

\section{Discussion}

Most of the cases of pulmonary hypoplasia are thought to be secondary to conditions that limit foetal lung growth. Inspite of arrested lung growth, the foetus survives and grows to full term in the uterus since its oxygen demand is met by the placenta. After birth, sudden death of the newborn occurs within few minutes due to failure of expansion of the extremely hypoplastic lungs. The pathological findings in pulmonary hypoplasia associated with $\mathrm{CDH}$ are reduced number of terminal bronchial divisions, delayed interstitial thinning and reduced pulmonary vascularisation [5]. In the past, the pathogenesis of pulmonary hypoplasia was thought to have occurred as a consequence of a cascade of effects which include, (a) a primary developmental defect in the diaphragm, (b) herniation of abdominal contents (c) lung hypoplasia resulting in severe postnatal respiratory distress and death [6].

More recent evidence seems to suggest a 'dual hit hypothesis' i.e. the involvement of a common genetic pathway that controls the development of both, the diaphragm and the lungs. The disruption of the Shhptc-Gli pathway and the Retinoid signaling pathway, (also active in both) are thought to be involved in the pathogenesis of $\mathrm{CDH}$ associated with pulmonary hypoplasia which may be a primary defect in itself. A nitrofen induced $\mathrm{CDH}$ mouse model demonstrated that lung hypoplasia may even precede the diaphragmatic defect as a primary congenital anomaly [7]. And down regulation of the Sonic hedgehog (Shh) expression in pulmonary hypoplasia is associated with CDH [5]. Shh inhibits lung fibroblast growth. Hence normal Shh expression may contribute to interstitial thinning occurring at the late glandular (6-16weeks) and early canalicular phase (16-26 weeks) of lung development. A disruption in this pathway would result in arrested lung development and CDH.

\subsection{Clinical Presentation:}

Common clinical presentations at birth in cases of $\mathrm{CDH}$ with pulmonary hypoplasia include respiratory distress with cyanosis, tachypnea, mediastinal shift, absent breath sounds on the affected side and bowel sounds in the chest on auscultation. Approximately $30-40 \%$ of cases with $\mathrm{CDH}$ have associated malformations, often involving cardiovascular, central nervous, musculoskeletal and/ or genitourinary systems [8]. In the present case, there were no other obvious anomalies.

\subsection{Management:}

Management involves immediate management of respiratory distress by placement of orogastric tube and securing the airway. The newborn is placed on a ventilator (High frequency oscillatory inhalation of NO in pulmonary hypertension). Extracorporeal Membrane Oxygenation (ECMO) has been used as part of treatment strategy [9]. Surgical repair of the diaphragm is done thoracoscopically by a technique known as plication of the diaphragm [10]. Surgical decompression of abdominal contents postnatally does not induce rapid lung growth. Prenatal management techniques include intrauterine surgery, foetal tracheal occlusion (FETO), and treatment with retinoic acid, vitamin A supplements [2].

\subsection{Prognosis:}

Foetuses/neonates with isolated left sided CDH, liver herniation and a lung-head ratio (LHR) of $<1.0$ have a poor prognosis $[11,12,4]$. LHR of $>1.4$ have a better prognosis with respect to survival. In our case, the defect was large, involving the entire left dome, with herniated contents including the entire small intestines, parts of the large bowel, stomach, spleen, left lobe of liver and associated with extremely hypoplastic both lungs.

\section{Conclusion}

- The maturational delay in Shh expression may be critical to the development of pulmonary hypoplasia associated with $\mathrm{CDH}$

- A better understanding of the Shh signaling pathway and its role in normal lung growth and development is required to understand the effect of its aberrant expression in $\mathrm{CDH}$ and lung Hypoplasia.

- In rural areas of India, people are still unaware about importance of antenatal checkups, which could diagnose $\mathrm{CDH}$ during early pregnancy.

- With the advent of better antenatal diagnosis and neonatal care, the chances of survival in CDH have improved. However, there still remains a significant risk of death and complications in infants with CDH. 
- Foetuses/neonates with an isolated left sided CDH have a poor prognosis especially when herniated contents include the liver, spleen etc.

- With huge CDH, severely hypoplastic lungs and herniated liver this baby was doing well in the uterus but was "Born to Die".

\section{Acknowledgements}

My sincere thanks to H.O.D. Department of Obstetrics and Gynaecology and Dr. Mrs. S.P. Jog Prof. and Ex. H.O.D Department of Anatomy, M.I.M.E.R Medical College, Talegaon Dabhade

\section{References}

[1] Keith L. Moore, T.V.N. Persaud, Mark G. Torchia, The Developing Human (Saunders, Philadelphia, Elsevier)

[2] Jan A Deprest, Kypros Nicolaides, Eduard Gratacos, Fetal Surgery for Congenital Diaphragmatic Hernia Is Back from Never Gone, Fetal Diag Ther, $(29$,$) 2011, 6-17.$

[3] http://emedicine.medscape.com/article/978118-overview

[4] Ramona Mandrusca, ES Boia, C Popoiu, Luminita Vrinceanu, Congenital diphragmatic hernia, Jurnalul pediatrului, (IX,) 2006, 3334.

[5] Sharon Unger, Ian Copland, Dick Tibboel, Martin Post, Down-Regulation of Sonic Hedgehog Expression in Pulmonary Hypoplasia Is Associated with Congenital Diaphragmatic Hernia, American journal of pathology, 162(2),2003, 547- 555.

[6] Mark D. Miller, Melanie A Marty, Impact of Environmental Chemicals on Lung Development, Environmental health practices, (118), 2010, 1155-1163.

[7] Richard Keijzer, Jason Liu, Julie Deimling, Dick Tibboel, Martin Post, Dual-Hit Hypothesis Explains Pulmonary Hypoplasia in the Nitrophen Model of Congenital Diaphragmatic Hernia, American journal of pathology, 156(4), 2000, 1299-1306. [8] Barbara R. Pober, Overview of Epidemiology, Genetics, Birth defects, and Chromosome Abnormalities Associated with CDH, $\mathrm{A} m$ j med genet. $\mathrm{c}$ semin genet., 145C(2, ) 2007, 158-171.

[9] Tovar, Congenital Diaphragmatic Hernia, Orphanet journal of rare diseases, 2012, 7:1

[10] Becmeur F, Talon I, Schaarschmidt K, Philippe P, Moog R. Kauffmann I, Schultz A et al. Thoracoscopic diaphragmatic eventration repair in children: about 10 cases, J. pediatr. Surg, 40 (11), 2005, 1712-5..

[11] Albanese CT, Lopoo J, Goldstein RB, Filly RA, Feldstein VA, Calen PW et al. Fetal liver position and perinatal outcome for congenital diaphragmatic hernia, Am j respir cell mol bio, 42(3), 2010, 276-85.

[12] J. Jani, R.L. Kelle, A. Benachi, K.H. Nicolaides, R. Farve, E. Gratacos et al., Prenatal prediction of survival in isolated left-sided diaphragmatic hernia, ultrasound obstet. Gynecol, (27), 2006, 18-22. 